\title{
Analysis and determinants of Chinese navy personnel health status: a cross-sectional study
}

\author{
Shali Xie ${ }^{1 *}$, Hui Lin², Yi Meng ${ }^{3}$, Jundong Zhư ${ }^{4}$, Yanqi Zhang ${ }^{5}$, Ling Zhang ${ }^{1}$ and Gaoming Li ${ }^{5}$
}

\begin{abstract}
Background: There have been very few studies analyzing the relationship of physical and mental health status with health behaviors and deployment status in Chinese navy personnel. Thus, we undertook this survey to assess this relationship and identify specific factors affecting the physical and mental health status.

Methods: The subjects enrolled in this study were selected from four units of the active-duty navy personnel in China, based on a cluster random sampling design. A total of 1200 Chinese navy personnel participated and completed the questionnaire survey that included veteran SF-36 form and a self-designed questionnaire regarding their sociodemographic characteristics, deployment status, self-rated health status and health behaviors. Totally 1200 questionnaires were distributed to different participants, while 1083 valid questionnaires were included in the final analysis. All data were analyzed using SPSS18.0 software.

Results: Based on the information provided by navy personnel, 17.82, 35.09 and 23.08\% rated their health as excellent, very good and good, respectively. The mean score of physical component summary (PCS) and mental component summary (MCS) was 50.53 and 41.39, respectively. Length of service, binge drinking, regular drinking and BMI appeared to be associated with PCS score, while household income, binge drinking and BMI affected MCS score. Deployment status and smoking exhibited no significant association with PCS and MCS scores.

Conclusions: Our study suggested that the sociodemographic factors like length of service and household income, along with behavioral risk factors like binge drinking, regular drinking and body mass index (BMI), seem to affect the physical and mental health status of Chinese navy personnel. However, additional data collection and more detailed analysis would still be required to develop a systematic, comprehensive and corresponding health education program to promote overall health status.
\end{abstract}

Keywords: Health status, Health related behaviors, Navy, Veterans SF-36, Military, China

\section{Background}

Military operations and related tasks require military personnel to maintain optimal physical and mental health fitness. Despite significant progress in defense technology, there remains a demand for high levels of physical fitness and physical functioning capacity [1]. Despite the younger average age of Chinese navy personnel in comparison with general population, there is still a need to explore their health behaviors and

\footnotetext{
* Correspondence: xslwjob@163.com

${ }^{1}$ Department of Health Education, College of Military Preventive Medicine,

Army Medical University, Chongqing 400038, China

Full list of author information is available at the end of the article
}

modifiable risks, and to understand levels of physical functioning and factors associated with higher levels of fitness [2].

Many behavioral factors or health habits, such as cigarette smoking, alcohol consumption, physical exercise, weight gain, eating habits and hours of sleep, were significantly associated with physical well-being and overall health. Among these factors, smoking and drinking are more prominent factors in the military population reported by many studies [2, 3]. For example, Kaly et al. [3] and LaBrie et al. [4] reported that active duty military personnel drink more heavily than their civilian counterparts and also engage in other health risk behaviors such

(c) The Author(s). 2018 Open Access This article is distributed under the terms of the Creative Commons Attribution 4.0 International License (http://creativecommons.org/licenses/by/4.0/), which permits unrestricted use, distribution, and reproduction in any medium, provided you give appropriate credit to the original author(s) and the source, provide a link to the Creative Commons license, and indicate if changes were made. The Creative Commons Public Domain Dedication waiver (http://creativecommons.org/publicdomain/zero/1.0/) applies to the data made available in this article, unless otherwise stated. 
as smoking, substance abuse and risky sexual behaviors. A survey on the alcohol drinking habit of Chinese naval pilots by Zhang et al. [5] reported that $74 \%$ of the survey population was drinking, and most of them started using alcohol after they joined the army, thereby implying that this can obviously affect flight safety and increase the risk of accidents. Specific smoking has been reported to be a major issue due to its high rate, which eventually impairs the troop readiness and productivity and increases the medical and training costs [6, 7]. An investigation on smoking behavior of Chinese naval aviators showed that total smoking rate was about $61 \%$, and of which $42 \%$ smokers suffered from one or more smoking-related diseases [8]. However, above two studies only focused on naval aviators in China, and little information is known about the prevalence of smoking and drinking in all branches of Navy. Moreover, other health risks including weight gain in military personnel as reported by studies in other countries, primarily due to poor dietary patterns and sedentary lifestyles in some cases, have been strongly linked with increased prevalence of acute and chronic illness, injury, healthcare costs, disability and absenteeism [9-11]. One domestic study described overweight or obesity along with other factors to be associated with obesity-related disorders such as hyperlipidemia and hyperuricemia in Chinese naval aviators [12]. However, no report was found regarding the association between weight gain and health status in Chinese naval personnel.

Moreover, the contextual factors affecting physical and mental health among general as well as military population have been well studied. Previous studies have indicated that demographic factors such as social support, marital status, household income and occupation significantly affect health outcomes [13]. For example, social support from financial assistance (e.g., household income), companionship and so on, shows a positive relationship with good perception of physical health and improving subjective well-being [13]. In addition, Smith et al. [1] found that being married and having a higher military rank are independently associated with more favorable health status. Other studies have indicated that military deployment is associated with adverse health related outcomes, including high-risk behavior and psychological morbidity from both real and perceived exposure $[14,15]$. But, there has been little information about the exact relationship between the deployment status and self-rated health in the Chinese navy personnel.

In summary, it is important to understand the various demographic and behavioral factors adversely affecting health. This would subsequently lead to the development of comprehensive and cost-effective intervention programs for health promotion. Therefore, based on previous studies, we proposed the following hypotheses: (1)
The health status of navy personnel is different from that of the general population, (2) certain sociodemographic factors and health hazard behaviors could influence their health status, and (3) military deployment is related to their health outcomes. Thus, in this study we investigated the health status of Chinese navy personnel, and explored the relationship between health status and sociodemographic factors, health-related behaviors and deployment status in a military cohort. We believe that these findings would be helpful in understanding the health of Chinese navy personnel, and can be useful in multiple ways like: (1) they can provide an indication about the quality of life of Chinese navy personnel, (2) specific information of health influencing factors can provide reference for their health education and health interventions, (3) these population-based results can also be used to compare the health of personnel within the navy or army or air force or with Chinese general population, (4) these results can also serve as a reference for exploring the health of particular sub groups within the military, such as the marines or coast guard, (5) the health status information can also provide a useful and comprehensive assessment of the health characteristics of these navy personnel and will be helpful in improving the health care delivery systems, along with their utility in the development of health promotion efforts.

\section{Methods \\ Participants}

This study was a cross-sectional survey of Chinese Navy personnel conducted between July and August 2016. The participants were recruited from four units of the active-duty navy members by cluster random sampling. Subjects who were not around when we conducted the survey were excluded from this study $(n=2$, due to illness and unable to reach the site). Our investigators explained to the participants the purpose of the survey, and how to fill out the questionnaire and the specific points for attention. Next, the participants were asked to fill out and return the questionnaire, and a total of 1200 participants participated in this exercise with all of them providing written informed consent. All the responses were anonymous and voluntary. The participation rate was $99.83 \%$. The study was conducted in compliance with the Helsinki Declaration and approved by the Ethics Committee of Army Medical University.

\section{Measurement}

\section{Veterans SF-36 form based data collection}

Participants' health status and health-related quality of life (HRQOL) were evaluated using the Short-Form 36 for veterans (SF-36 V), a version of the Short Form 36 (SF-36) health survey questionnaire, modified for use in military personnel $[1,16-18]$. The SF-36 measures eight 
health areas: physical functioning (PF), role limitation due to physical problems (RP), body pain (BP), general health $(\mathrm{GH})$, role limitation due to emotional problems $(\mathrm{RE})$, mental health $(\mathrm{MH})$, energy/vitality (VT), and social functioning (SF). Each area was scored from 0 to 100. SF-36 V differs from the original SF-36 as follows: $\mathrm{RP}$ and RE subscales are changed from a dichotomous scale to a 5-point scale to avoid floor and ceiling effects $[19,20]$ and improve the reliability and validity of the original version $[18,21]$. Physical Component Summary (PCS) and Mental Component Summary (MCS) scores, which represent subjective physical health and mental health respectively, were calculated from eight subscale scores by using standard SF-36 scoring mechanism as recommended [19]. PCS and MCS were norm-based and population-standardized with $0-100$ scoring range, mean of 50, and standard deviation of 10 . Higher scores on subscale and summary scales indicate better functioning in that domain and better health status or HRQOL [1]. SF-36 V was found to have high internal consistency across all eight domains in military populations [18, 21]. The self-rated health was assessed based on the response to the following question, "In general, would you say your health is excellent, very good, good, fair or poor?" The answers to this question were classified into two categories: a) excellent/very good/good, and b) fair/poor.

\section{Assessment of sociodemographic, body mass index (BMI) and behavioral risk factors}

To measure the health determinants, we used self-designed questionnaires to investigate demographic information, BMI and behavioral risk factors. The sociodemographic attributes included age, gender, nationality, marital status, education level, household income, residential location, and military-related information such as length of service, rank, and deployment status. Length of service was divided into four grades: $0-3$ years, $4-8$ years, 9-15 years, and $>16$ years, according to the period of rank. The service for 9 years or above was defined as longer service time. BMI $\left(\mathrm{kg} / \mathrm{m}^{2}\right)$ was calculated from self-reported height and weight, was defined as underweight $\left(<18.5 \mathrm{~kg} / \mathrm{m}^{2}\right)$, normal $\left(18.5-23.9 \mathrm{~kg} / \mathrm{m}^{2}\right)$, overweight $\left(24-27.9 \mathrm{~kg} / \mathrm{m}^{2}\right)$ and obese $\left(\geq 28 \mathrm{~kg} / \mathrm{m}^{2}\right)$, according to Chinese population standards [22]. The behavioral variables included smoking and drinking. Smoking was grouped as smoked $<20$ cigarettes/day, smoked $\geq 20$ cigarettes/day, never smoked and past smokers. Heavy smokers referred to the smokers who smoked $\geq 20$ cigarettes/day [23]. Drinking and binge drinking were grouped as everyday or almost every day, frequent, occasional and never. The frequencies were coded as follows: everyday or almost everyday $=6-7$ times $/$ week; Frequent $=1-5$ times $/$ week; Occasional $=3$ times or below/month. Binge drinking represented five or more drinks in one sitting [24]. The deployment status, included war-related military operations and non-war military operation, was classified as without (i.e., the participants have no deployment experience prior to the study) or with (i.e., the participants have deployment experience prior to the study) experience.

\section{Data analysis}

All data was entered in duplicate into the EpiData version3.1 database, and the SPSS18.0 software was used for data analysis. The data measurement was presented as mean \pm standard deviation. The independent variables were expressed as a rate or constituent ratio using descriptive statistics. One-way ANOVA test was used to analyze these variables and determine the difference among multiple groups. Significant variables determined by univariate analysis were entered into final multivariable linear regression and logistic regression model to predict health status. A $p$ value of $<0.05$ was considered to be statistically significant.

\section{Results \\ Demographic characteristics of the participants}

The final participation rate was $99.83 \%$ (1200 of 1202). A total of 1200 questionnaires were distributed to different participants and they all submitted their answers, thereby indicating a response rate of $100 \%$. Among the 1200 returned questionnaires, 117 questionnaires were excluded because of invalid or incomplete responses, and thus 1083 valid questionnaires were included in the analysis, indicating an effective rate of return as $90.25 \%$ (1083 of 1200). In 117 excluded questionnaires, except for one from a female soldier, the rest of 116 questionnaires were from males, aged 18-53 years, with an average age of $25.45 \pm 8.79$ years, and as to the rank, $33.33 \%$ of them were soldiers, $51.52 \%$ were sergeants, and $15.15 \%$ were officers. Their characteristics were not significantly different from those included in the analysis. Table 1 summarizes the demographic characteristics of the study population. Out of the 1083 participants, only 3 were females and the rest were males. The majority of the participants were Han population, less than 35 years old, with high school diploma or below, unmarried, from the countryside, and in service less than 9 years $(78.30 \%)$. Most of them hold sergeants ranks (56.14\%), followed by soldiers (30.93\%), and officers (12.93\%), which is consistent with the rank distribution in Chinese Navy. Therefore, the study is representing the whole Chinese Navy. Most of the participants had a household income of $<4000$ yuan/month (around 605 US dollar per month).

\section{Self-reported health behaviors, military exposures and BMI of participants}

As shown in Table 2, only less than $22 \%$ of the participants reported deployment experience, while most of 
Table 1 Social demographic data (Number of respondents = 1083)

\begin{tabular}{|c|c|c|}
\hline Characteristics & Number & Percent \\
\hline \multicolumn{3}{|l|}{ Age(years) } \\
\hline $17 \sim 24$ & 642 & 59.28 \\
\hline $25 \sim 34$ & 402 & 37.12 \\
\hline$\geq 35$ & 39 & 3.6 \\
\hline \multicolumn{3}{|l|}{ Race } \\
\hline Han & 1022 & 94.37 \\
\hline Minority & 61 & 5.63 \\
\hline \multicolumn{3}{|l|}{ Length of service(years) } \\
\hline $0 \sim 3$ & 473 & 43.67 \\
\hline $4 \sim 8$ & 375 & 34.63 \\
\hline $9 \sim 15$ & 197 & 18.19 \\
\hline$\geq 16$ & 38 & 3.51 \\
\hline \multicolumn{3}{|l|}{ Marital status } \\
\hline Unmarried & 847 & 78.21 \\
\hline Married, living together & 95 & 8.77 \\
\hline Married, but separated & 141 & 13.02 \\
\hline \multicolumn{3}{|l|}{ Education } \\
\hline High school diploma or below & 599 & 55.31 \\
\hline Some college & 288 & 26.59 \\
\hline Bachelor's degree or above & 196 & 18.1 \\
\hline \multicolumn{3}{|l|}{ Residential Location } \\
\hline Rural area & 682 & 62.97 \\
\hline City & 401 & 37.03 \\
\hline \multicolumn{3}{|l|}{ Rank } \\
\hline Soldier & 335 & 30.93 \\
\hline Sergeant & 608 & 56.14 \\
\hline Officer & 140 & 12.93 \\
\hline \multicolumn{3}{|l|}{ Household income(yuan/month) } \\
\hline$<2000(\sim 302$ US dollar) & 473 & 43.67 \\
\hline 2000 to 4000 ( 302 to 605 US dollar) & 439 & 40.54 \\
\hline > 4000( 605 US dollar) & 171 & 15.79 \\
\hline
\end{tabular}

participants reported no deployment experience. In addition, among the participants with modifiable risk behaviors, more than half of them were smokers, but most of them smoked $<20$ cigarettes/day. In the case of alcohol use, most of the participants reported drinking $(82.09 \%)$, and nearly half of them $(46.90 \%)$ reported to have been involved in binge drinking (five or more drinks in one sitting). Based on BMI, the majority of participants were normal $(65.93 \%, n=714)$.

\section{Self-rated health status along with PCS and MCS scores of participants}

More than $50 \%$ of the participants reported very good or excellent physical health, as shown in Table 3. As for the
Table 2 Self-reported military exposures and health-related indicators of participants

\begin{tabular}{lll}
\hline Variable & Number & Percent \\
\hline Military exposures & & \\
Past deployment status & & \\
$\quad$ Deployment experience & 233 & 21.51 \\
$\quad$ No deployment experience & 850 & 78.49 \\
BMI $\left(\mathrm{kg} / \mathrm{m}^{2}\right)$ & & \\
$<18.5$ & 34 & 3.14 \\
$18.5 \sim 23.9$ & 714 & 65.93 \\
$24.0 \sim 27.9$ & 288 & 26.59 \\
$\geq 28.0$ & 47 & 4.34
\end{tabular}

Health-related behaviors

smoking

Smoked<20cigarettes/day

$\begin{array}{ll}501 & 46.26 \\ 63 & 5.82\end{array}$

Smoked $\geq 20$ cigarettes/day

5.82

Never smoked

$463 \quad 42.75$

Past smokers

$\begin{array}{ll}56 & 5.17\end{array}$

Drinking

Everyday or almost everyday $\quad 52 \quad 4.80$

Frequent $209 \quad 19.30$

$\begin{array}{lll}\text { Occasional } & 628 & 57.99\end{array}$

$\begin{array}{lll}\text { Never } & 194 & 17.91\end{array}$

Binge drinking

Everyday or almost everyday $\quad 18 \quad 1.66$

$\begin{array}{lll}\text { Frequent } & 108 & 9.97\end{array}$

$\begin{array}{lll}\text { Occasional } & 382 & 35.27\end{array}$

Never $\quad 575 \quad 53.10$

Note: everyday or almost everyday $=6-7$ times/week; Frequent $=1-5$ times/ week; Occasional $=3$ times or below/month

Veterans SF-36 based assessment of functional status, mean scores of the 8 Veterans SF-36 scales ranged from 63.88 to 85.94 , with the highest mean for physical functioning. Accordingly, the summary score of PCS was above the mean of 50 for the Chinese general population. However, MCS was about 8 point lower than Chinese general population, indicating a less favorable mental health state.

\section{Effect of social demographic factors on the health status} of study participants

To assess the effect of sociodemographic factors on the health status of the participants, we performed a univariate analysis, as shown in Table 4. Except race, age, marital status, educational level, and residential location, the factors that showed significant $(P<0.01)$ association with PCS score were the length of service and rank, while the rank and household income showed significant association with MCS score $(P<0.05)$. The participants who 
Table 3 Self-rated health status and PCS, MCS scores

\begin{tabular}{|c|c|c|}
\hline Variable & Number & Percent \\
\hline \multicolumn{3}{|l|}{ General health } \\
\hline \multicolumn{3}{|c|}{ In general, would you say your health is } \\
\hline Excellent & 193 & 17.82 \\
\hline Very good & 380 & 35.09 \\
\hline Good & 250 & 23.08 \\
\hline Fair & 235 & 21.7 \\
\hline Poor & 25 & 2.31 \\
\hline SF-36 V & Mean \pm SD & $<$ Mean (\%) \\
\hline \multicolumn{3}{|l|}{ Physical } \\
\hline PF & $85.94 \pm 19.88$ & $346(31.95)$ \\
\hline $\mathrm{RP}$ & $70.78 \pm 26.50$ & $475(43.86)$ \\
\hline $\mathrm{BP}$ & $79.22 \pm 21.02$ & $521(48.11)$ \\
\hline $\mathrm{GH}$ & $69.57 \pm 19.91$ & $509(47.00)$ \\
\hline \multicolumn{3}{|l|}{ Mental } \\
\hline RE & $72.31 \pm 26.71$ & $436(40.26)$ \\
\hline $\mathrm{MH}$ & $64.50 \pm 16.53$ & $551(50.88)$ \\
\hline $\mathrm{VT}$ & $63.88 \pm 17.66$ & $484(44.69)$ \\
\hline SF & $77.11 \pm 15.79$ & $411(37.95)$ \\
\hline \multicolumn{3}{|c|}{ Summary scores ${ }^{\mathrm{a}}$} \\
\hline PCS & $50.53 \pm 9.24$ & $448(41.37)$ \\
\hline MCS & $41.39 \pm 11.30$ & $503(46.46)$ \\
\hline
\end{tabular}

Note: ${ }^{\text {a }}$ standardized to Chinese population with a mean of 50 and standard deviation of 10; higher scores denote better health

were in a longer service time had lower PCS score. Especially the PCS score in the participants over 9 years of service was significantly lower than those with fewer than 3 years of service $(P<0.05)$. Interestingly, the PCS score in the sergeants was significantly lower than that in the soldiers and officers $(P<0.05)$. As to MCS, the participants with higher household income displayed higher MCS score, especially group with $>4000$ yuan income had significantly higher MCS score than the group with $<2000$ yuan $(P<0.05)$. The sergeant's MCS score was lowest, and significantly lower than the officers $(P<0.05)$.

\section{Analysis of the health status relationship with}

\section{deployment status, BMI and health-related behaviors}

As shown in Table 5, the PCS and MCS scores showed significant association with all factors $(p<0.05, p<$ 0.01 ), with the exception of mean MCS score and deployment status ( $>00.05$ ). Moreover, participants with deployment experience displayed lower PCS score than those without. Similarly, the heavy smokers $(\geq 20$ cigarettes/day) or obese $\left(\mathrm{BMI} \geq 28 \mathrm{~kg} / \mathrm{m}^{2}\right)$ participants had lower PCS and MCS scores, and were below the Chinese general population mean of 50. Also, the higher frequency of drinking or binge drinking correlated with lower PCS and MCS scores.
Multiple linear regression analysis of health status with sociodemographic characteristics, health-related behaviors and BMI

To further control the effect of known confounding factors such as age and education, we performed a multivariate linear regression analysis of the significant variables determined by univariate analysis, including the length of service, rank, household income, past deployment status, BMI, smoking, drinking and binge drinking, and the results have been summarized in Table 6 . Among the different sociodemographic characteristics, the independent influencing factors that significantly correlated with PCS and MCS scores were length of service and household income, respectively. Participants with long service years were significantly more likely to have lower PCS score compared with soldiers who had a short service life. Similarly, the participants with high household income level were observed to have high MCS score.

In terms of health-related behaviors and BMI, the independent influencing factors for PCS score were frequent drinking, binge drinking and $\mathrm{BMI}$, while for MCS score, it was only binge drinking and BMI. Specially, the participants who were overweight or obese and accustomed to binge drinking had lower PCS and MCS scores, while participants who were accustomed to frequent drinking, only had lower PCS score.

\section{Logistic regression results predicting self-rated general health}

All significant predictors from the univariate analysis were also entered into a final multivariable logistic regression model. As shown in Table 7, only the length of service, BMI, and binge drinking remained significant predictors for self-rated general health. Similar to the multiple linear regression model described above, individuals who were binge drinkers, had longer length of military service, and were overweight or obese, had higher risk of poor self-rated health than individuals who had no binge drinking habits, had a shorter service life, and normal BMI.

\section{Discussion}

This cross-sectional study has investigated various determinants affecting the health status of Chinese navy personnel, using a specific population sample with an emphasis on health related behavioral factors. To our knowledge, this is the first study in China, to assess the navy personnel health status based on PCS and MCS scores, and their relationship with different health risk behaviors. This study would eventually have important implications for China's public health system, especially for the health of Chinese military personnel.

In the present study, approximately $76 \%$ of the participants reported good health, indicating that most of navy 
Table 4 Univariate analysis of sociodemographic items related to PCS and MCS scores among the participants

\begin{tabular}{|c|c|c|c|c|c|c|}
\hline \multirow[t]{2}{*}{ Variable } & \multicolumn{3}{|l|}{ PCS } & \multicolumn{3}{|l|}{ MCS } \\
\hline & Mean \pm SD & Levene & $F / X^{2}(Z)$ & Mean \pm SD & Levene & $F / X^{2}(Z)$ \\
\hline Race & & 0.28 & $F=0.66$ & & 0.01 & $F=0.86$ \\
\hline Han & $50.58 \pm 9.19$ & & & $41.31 \pm 11.29$ & & \\
\hline Minority & $49.58 \pm 10.11$ & & & $42.71 \pm 11.44$ & & \\
\hline Age(years) & & 0.71 & $F=2.24$ & & 0.01 & $F=0.64$ \\
\hline $17 \sim 24$ & $50.83 \pm 9.47$ & & & $41.03 \pm 11.19$ & & \\
\hline $25 \sim 34$ & $50.21 \pm 8.96$ & & & $41.83 \pm 11.52$ & & \\
\hline$\geq 35$ & $47.54 \pm 8.10$ & & & $41.82 \pm 11.08$ & & \\
\hline Length of service(years) & & 0.40 & $F=3.848^{* *}$ & & 0.49 & $F=0.59$ \\
\hline $0 \sim 3$ & $51.26 \pm 9.56$ & & & $41.12 \pm 11.15$ & & \\
\hline $4 \sim 8$ & $50.44 \pm 8.88$ & & & $41.97 \pm 11.29$ & & \\
\hline $9 \sim 15$ & $49.55 \pm 9.06^{\mathrm{a}}$ & & & $40.79 \pm 11.53$ & & \\
\hline$\geq 16$ & $46.63 \pm 8.87^{\mathrm{ab}}$ & & & $41.60 \pm 12.41$ & & \\
\hline Marital status & & 1.42 & $F=2.29$ & & 0.15 & $F=1.40$ \\
\hline Unmarried & $50.81 \pm 9.27$ & & & $41.50 \pm 11.27$ & & \\
\hline Married, but separated & $49.17 \pm 9.48$ & & & $41.67 \pm 11.15$ & & \\
\hline Married, living together & $49.62 \pm 8.56$ & & & $39.42 \pm 11.91$ & & \\
\hline Education & & 0.91 & $F=2.39$ & & 2.22 & $F=0.87$ \\
\hline High school diploma or below & $50.04 \pm 9.41$ & & & $40.94 \pm 11.35$ & & \\
\hline Some college & $50.59 \pm 9.30$ & & & $41.89 \pm 11.80$ & & \\
\hline Bachelor's degree or above & $51.71 \pm 8.62$ & & & $41.82 \pm 10.44$ & & \\
\hline Residential Location & & $6.62^{* *}$ & $Z=-0.91$ & & 0.09 & $F=0.92$ \\
\hline Rural area & $50.46 \pm 8.90$ & & & $41.61 \pm 11.27$ & & \\
\hline City & $50.56 \pm 9.83$ & & & $40.92 \pm 11.37$ & & \\
\hline Rank & & 1.61 & $F=8.17^{* *}$ & & 1.66 & $F=2.62^{*}$ \\
\hline Soldier & $51.76 \pm 9.17$ & & & $41.85 \pm 11.34$ & & \\
\hline Sergeant & $49.50 \pm 9.34^{a}$ & & & $40.84 \pm 11.44$ & & \\
\hline Officer & $51.90 \pm 8.57^{b}$ & & & $42.49 \pm 10.57^{b}$ & & \\
\hline Household income(yuan/month) & & 1.59 & $F=0.69$ & & 0.76 & $F=2.92^{*}$ \\
\hline$<2000(\sim 302$ US dollar) & $50.12 \pm 9.64$ & & & $40.45 \pm 11.51$ & & \\
\hline 2000 to 4000 ( 302 to 605 US dollar) & $50.84 \pm 8.74$ & & & $41.82 \pm 10.93$ & & \\
\hline > 4000( 605 US dollar $)$ & $50.63 \pm 9.50$ & & & $42.63 \pm 11.64^{a}$ & & \\
\hline
\end{tabular}

Note: ${ }^{*} p<0.05,{ }^{* *} p<0.01$; The ANOVA test was applied when variance homogeneity was satisfied (F-measure); non parametric rank test was applied when missing variance (Z-measure or Chi square value)

${ }^{a}$ Mean values were significantly different from those of the first group $(p<0.05)$

${ }^{\mathrm{b}}$ Mean values were significantly different from those of the second group $(p<0.05)$

soldiers and officers feel better about their health status. This information was consistent with study by Smith et al. [25], which showed that most respondents $(69.8 \%)$ of US Navy and Marine Corps personnel reported their health as being very good or excellent. However, in the 8 domains of HRQOL, navy personnel had lower scores from 5 to 18 points than the general Chinese population aged 14 44 years, indicating that HRQOL in these domains was less favorable [26]. In comparison with US military samples of Millennium Cohort Study (where navy population accounted for $23.6 \%$ ), our study participants showed 6 subscales that were lower from 4 to 13 points except for BP and VT subscale scores which tended to be better than that of US military samples [27].

Based on SF-36 V evaluation results, we observed that the PCS score was above the Chinese population mean of 50, indicating that the navy's physical health status was better than general Chinese population. Moreover, the MCS score was about 8 points lower than general 
Table 5 Relationships of PCS and MCS scores with deployment status and health-related indicators of participants

\begin{tabular}{|c|c|c|c|c|c|c|}
\hline \multirow[t]{2}{*}{ Variable } & \multicolumn{3}{|l|}{ PCS } & \multicolumn{3}{|l|}{ MCS } \\
\hline & Mean \pm SD & Levene & $F / X^{2}(Z)$ & Mean \pm SD & Levene & $F / X^{2}(Z)$ \\
\hline Past deployment status & & 0.65 & $F=5.74^{*}$ & & 0.32 & $F=0.16$ \\
\hline Deployment experience & $49.24 \pm 8.90$ & & & $41.65 \pm 11.58$ & & \\
\hline No deployment experience & $50.88 \pm 9.31$ & & & $41.32 \pm 11.23$ & & \\
\hline $\mathrm{BMI}\left(\mathrm{kg} / \mathrm{m}^{2}\right)$ & & 0.63 & $F=3.86^{*}$ & & 0.26 & $F=2.76^{*}$ \\
\hline$<18.5$ & $49.11 \pm 10.12$ & & & $45.09 \pm 10.81$ & & \\
\hline $18.5 \sim 23.9$ & $50.99 \pm 9.15$ & & & $41.61 \pm 11.08$ & & \\
\hline $24.0 \sim 27.9$ & $50.10 \pm 9.14$ & & & $40.74 \pm 11.58^{\mathrm{a}}$ & & \\
\hline$\geq 28.0$ & $46.96 \pm 9.99^{b c}$ & & & $39.40 \pm 12.72^{\mathrm{a}}$ & & \\
\hline Smoking & & 2.16 & $F=2.84^{*}$ & & 1.60 & $F=2.96^{*}$ \\
\hline Smoked<20cigarettes/day & $50.11 \pm 9.40$ & & & $41.85 \pm 10.91$ & & \\
\hline Smoked $\geq 20$ cigarettes/day & $46.86 \pm 10.31$ & & & $34.49 \pm 10.61^{a}$ & & \\
\hline Never smoked & $51.33 \pm 8.70^{\mathrm{ab}}$ & & & $41.26 \pm 11.57^{b}$ & & \\
\hline Past smokers & $49.37 \pm 11.06$ & & & $40.40 \pm 12.40^{b}$ & & \\
\hline Drinking & & $2.70^{*}$ & $x^{2}=8.56^{*}$ & & 0.78 & $\mathrm{~F}=8.15^{* *}$ \\
\hline Everyday or almost everyday & $48.15 \pm 10.29$ & & & $35.05 \pm 11.24$ & & \\
\hline Frequent & $49.46 \pm 9.71$ & & & $40.11 \pm 11.30^{\mathrm{a}}$ & & \\
\hline Occasional & $50.80 \pm 9.16$ & & & $42.49 \pm 11.03^{\mathrm{ab}}$ & & \\
\hline Never & $51.15 \pm 8.67^{\mathrm{a}}$ & & & $40.85 \pm 11.53^{\mathrm{a}}$ & & \\
\hline Binge drinking & & $2.78^{*}$ & $x^{2}=16.66^{* *}$ & & 2.60 & $F=5.56^{* *}$ \\
\hline Everyday or almost everyday & $43.68 \pm 11.27$ & & & $32.31 \pm 10.79$ & & \\
\hline Frequent & $48.79 \pm 9.99^{a}$ & & & $39.29 \pm 12.71^{a}$ & & \\
\hline Occasional & $50.02 \pm 9.23^{a}$ & & & $41.67 \pm 10.67^{\mathrm{a}}$ & & \\
\hline Never & $51.40 \pm 8.90^{\mathrm{abc}}$ & & & $41.87 \pm 11.31^{\mathrm{ab}}$ & & \\
\hline
\end{tabular}

Note: ${ }^{*} p<0.05,{ }^{* *} p<0.01$; The ANOVA test was applied when variance homogeneity was satisfied (F-measure); non parametric rank test was applied when missing variance (Z-measure or Chi square value)

${ }^{a}$ Mean values were significantly different from those of the first group $(p<0.05)$

${ }^{b}$ Mean values were significantly different from those of the second group $(p<0.05)$

${ }^{c}$ Mean values were significantly different from those of the third group $(p<0.05)$

everyday or almost everyday =6-7 times/week; Frequent $=1-5$ times/week; Occasional $=3$ times or below/month

Table 6 Multiple linear regression analysis of health status with sociodemographic characteristics, BMI and health behavior

\begin{tabular}{|c|c|c|c|c|c|c|c|c|c|}
\hline health status & Variables & Beta & SE & Standardized Beta & Adjusted R Square & $t$ & p & Durbin-Watson & $\mathrm{F}$ \\
\hline \multirow[t]{5}{*}{ PCS } & & & & & & & & 1.603 & $7.95^{* *}$ \\
\hline & Binge drinking & -2.454 & 1.069 & -.074 & 0.011 & -2.295 & .022 & & \\
\hline & Length of service & -1.384 & .628 & -.071 & 0.010 & -2.204 & .028 & & \\
\hline & Regular drinking & -2.793 & 1.239 & -.072 & 0.009 & -2.255 & .024 & & \\
\hline & BMl & -1.927 & .879 & -.070 & 0.009 & -2.192 & .029 & & \\
\hline \multirow[t]{4}{*}{ MCS } & & & & & & & & 1.71 & $9.46^{* *}$ \\
\hline & Binge drinking & -2.414 & .658 & -.112 & 0.003 & 3.671 & .000 & & \\
\hline & Household income & 1.885 & .671 & .086 & 0.006 & 2.811 & .005 & & \\
\hline & BMl & -2.003 & .799 & -.077 & 0.007 & -2.507 & .012 & & \\
\hline
\end{tabular}

Note: ${ }^{* *} p<0.01$. Adjustments for race, age, education, marital status and residential location were made in the analysis 
Table 7 Logistic regression results predicting self-rated general health

\begin{tabular}{llllll}
\hline Predictor & Beta & SE & Wald & $p$ & OR (95\% Cl) \\
\hline Binge drinking & -0.251 & 0.154 & 3.943 & 0.047 & $0.737(0.545$ to 0.996$)$ \\
Length of service (years) & -0.356 & 0.091 & 9.794 & 0.002 & 0.752 (0.629 to 0.899) \\
BMI & -0.285 & 0.118 & 4.507 & 0.034 & 0.778 (0.617 to 0.981)
\end{tabular}

Adjustments for race, age, education, marital status and residential location were made in the analysis

Chinese population. The reason may be the job environment and job characteristics that navy officers and soldiers confronted were under greater psychological pressure, and they could have higher probability suffering from mental disorder in comparison with people of similar age in Chinese population [28, 29]. Although the MCS score of the navy at the survey time was in the normal range considering their occupation, their mental health status may need extra attention to meet the requirements of modern military construction and high-tech war in the future.

Furthermore, in the present study we have identified relationship through multivariate model, of number of sociodemographic and military characteristics, including age, educational attainment, marital status, race, household income, residential location, rank, duration of military service, with health status. The results showed that the length of service and household income were independently associated with physical and mental health status, respectively. Importantly, we noticed that participants with long service time had lower PCS scores, thereby suggesting more physical health problems in these participants. The result was in line with the studies of Tian et al. [30] and Smith et al. [1]. Tian et al. found that longer military service correlated with lower score of physical functioning $(\mathrm{p}<0.001)$, while Smith et al. found that military members with longer lengths of service had less favorable physical health $(\mathrm{p}<0.05)$. Our finding is also independently confirmed with the observation that longer service times showed association with self-rated less than good health (poor). This could be attributed to the fact that navy personnel with long military service completed more tasks of combat training mission, and long period also exposure them to various health hazards and intense and stressful environments, thereby resulting in greater risk to their health.

Interestingly, the participants with higher household income displayed higher MCS score, representing more favorable mental health status than soldiers with less household income. Feng et al. [31] reported that family financial difficulties influenced the mental health status of navy officers and soldiers. The findings of our study are basically in agreement with previous studies. The reasons may be related to more psychological pressure on navy personnel with lower household income. If psychological pressure could not be alleviated, it would probably lead to poor mental health status. Thus, this observation in our study will have important implication for health professionals to identify those personnel, who are most likely in need of help, and eventually allocate the health care resources, accordingly.

Additionally, higher rates of health risk behaviors such as cigarette smoking and alcohol misuse among veterans have been reported in comparison to non-veterans in various studies $[2,3]$. The smoking prevalence estimated by our study in navy personnel was lower than the civilian rate of $59.7 \%$ as reported by Xu et al. in 2010 [32], but it was significantly higher than prevalence of current smoking (17.9\%) of navy personnel in Sri Lanka [33] and 2005 estimate of US Navy soldiers (32\%) [34]. However, the navy personnel had significantly higher drinking rate than general population (39.6\%) as reported by $\mathrm{Ma}$ et al. [35] in 2007. LeardMann et al. [36] documented that $32.6 \%$ of US Marine Corps recruits were high-risk and potentially problematic drinkers. Comparably, our study also showed that nearly $47 \%$ of the participants in our study have experienced binge drinking. The studies by Widome et al. [2] and Ryan et al. [37] have demonstrated that military personnel are more likely to have higher BMIs, and thus would be categorized into the overweight category. Similarly, our study observed that about $26 \%$ of the participants were overweight, which was higher than the overweight rate $(22.8 \%)$ in Chinese population over the age of 18 years, as reported by a national survey in 2005 [38]. There are indications about overweight or obesity association with long-term drinking, smoking, and lack of exercise, and it has been observed that navy personnel while on duty have irrational dietary plans. For example, when the navy personnel are on duty at sea, they consume more red meat and processed meat, but fewer fruits and vegetables and also no engaged in regular exercise routine than during other time $[39,40]$.

Finally, our study also examined the relationship of health status with health-related behaviors, BMI and deployment status of navy members. Our analysis identified that binge drinking and BMI were independently associated with both physical and mental health status, whereas frequent drinking was independently associated 
only with physical health status outcomes. The participants with higher physical and mental health scores were observed to be involved in significantly less risky behaviors like binge drinking, regular drinking, and BMI, and reported significantly good self-rated health. It again confirmed that binge drinking and BMI were associated with self-rated fair/poor general health. Overall it can be deduced that increased awareness about the health hazards of alcohol misuse should be emphasized and some alcohol reduction strategies for health promotion should be introduced. Moreover, effective measures on modifying BMI in military need to be carried out and implemented. Relevant departments need to invest the necessary funds to improve the living facilities and environmental conditions of the troops, especially provide adequate fresh vegetables and fruits to soldiers on duty or training at sea.

Although deployment status and smoking were significant predictors in the preliminary variance analysis model, they did not remain significant in the final analysis. This observation was contrary to the results of studies by Ryan et al. [37] and Robyn et al. [15] and Jahnke et al. [6]. Ryan and Robyn suggested that the psychological and physical effects of deployment may have a greater impact on health. At least some military activities might be resulting in mental and physical health deterioration. In a population-based study conducted on U.S. Marines, Robyn et al. [15] found that significant number of individuals in the war-deployed cohort were likely to have a posttraumatic stress disorder (PTSD) diagnosis than individuals in the non-war-deployed cohort $(\mathrm{p}<0.01)$. The HRQOL reported by these veterans has also been shown to be significantly less favorable [41]. However, in the present study, deployment status had no significant effect on either the health scores of PCS, MCS or self-rated general health. This difference could be attributed to the fact that the participants in their study were mainly involved in war-related military operations, such as Gulf War, Vietnam War and Operation Iraqi Freedom, while Chinese navy personnel has spent relatively little time waging conventional battles and has only engaged on numerous non-war military actions, for instance, peacekeeping operations, earthquake relief actions, security operations.

The study by Jahnke et al. [6] analyzed the impact of tobacco use on military health and readiness. Interestingly, we observed no significant association of smoking with PCS and MCS scores in the final model, and this observation was consistent with the finding by Darviri et al. [42], who also showed that smoking did not exhibit significant association with self-rated health. Again, this could partly be due to the fact that (1) navy soldiers are young, and the disease caused by smoking takes a long time to show; and (2) previous study have shown that smoking is considered to be an accepted stress relief method. However, further studies would be required to help confirm the specific reasons.

Our study has certain limitations. Firstly, it is a cross-sectional study and thus we cannot make definitive conclusion about the observed associations. Secondly, weight was recorded in a self-report form and was likely to be underestimated. This would result in underreporting of BMI. Thirdly, there were 117 participants who did not provide complete information. However, their characteristics were not significantly different from those included in the analysis, and non-responders are not in high number. Thus, we expect that exclusion of these non-responders did not influence the statistical analyses. Moreover, sample size was not determined, since it could meet the requirements for ANOVA and regression analysis.

\section{Conclusion}

In conclusion, our study provided the preliminary information on the health status (based on physical and mental scores) and various factors affecting it in Chinese navy personnel. Our study demonstrated that some sociodemographic and health-related behavioral factors such as, length of service, frequently drinking, binge drinking and BMI, influence the health status. This initial baseline information would be helpful for designing the health promotion strategy for military personnel in China and assisting health policy makers in preparing for appropriate health, nutrition, occupational environment, and social support guideline for the Chinese navy personnel. However, further research would be required by including large data points to specifically focus on the different health risk factors, and evaluating the dynamic changes in the health status. These interventions will definitely help to improve the overall health of the navy personnel and subsequently improving their combat capability.

\section{Abbreviations \\ MCS: Mental component summary; PCS: Physical component summary; SF-36: Short form 36}

\section{Acknowledgments}

We would like to thank all the Navy personnel for their cooperation and junior officers of basic units that helped us to organize the field survey and data collection.

\section{Funding}

The study was funded by Military Science Project of National Social Science Foundation, China (No. 15GJ003-169).

\section{Availability of data and materials}

The datasets used and/or analyzed during the current study available from the corresponding author on reasonable request.

Authors' contributions

SX conceived and designed the study, analyzed and interpreted data and prepared the first draft of manuscript. HL developed the protocol, 
coordinated the fieldwork and data management, interpreted data and helped in manuscript writing. YM analyzed spatial data and helped in manuscript writing. JZ involved in design, data interpretation and manuscript writing. YZ, $L Z$, and GL collected and managed data and samples, and developed databases. All authors read and approved the final manuscript.

\section{Ethics approval and consent to participate}

Informed written consent was obtained from participants prior to data collection. The study was conducted in compliance with the Helsinki Declaration and approved by the Ethics Committee of Army Medical University.

\section{Consent for publication}

Not applicable.

\section{Competing interests}

The authors declare that they have no competing interests.

\section{Publisher's Note}

Springer Nature remains neutral with regard to jurisdictional claims in published maps and institutional affiliations.

\section{Author details}

${ }^{1}$ Department of Health Education, College of Military Preventive Medicine, Army Medical University, Chongqing 400038, China. ${ }^{2}$ Department of Tropical Epidemiology, College of Military Preventive Medicine, Army Medical University, Chongqing 400038, China. ${ }^{3}$ Department of Social Work, Social and Public Management School, Chongqing Technology and Business University, Chongqing 400067, China. ${ }^{4}$ Department of Nutrition and Food Hygiene, College of Military Preventive Medicine, Army Medical University, Chongqing 400038, China. ${ }^{5}$ Department of Health Statistics, College of Military Preventive Medicine, Army Medical University, Chongqing 400038, China.

\section{Received: 14 March 2017 Accepted: 27 June 2018}

\section{Published online: 11 July 2018}

\section{References}

1. Smith TC, Zamorski M, Smith B, Riddle JR, LeardMann CA, Wells TS, Engel CC, Hoge CW, Adkins J, Blaze D. The physical and mental health of a large military cohort: baseline functional health status of the millennium cohort. BMC Public Health. 2007;7:340.

2. Widome R, Laska MN, Gulden A, Steven S, Lust K. Health risk behaviors of Afghanistan and Iraq war veterans attending college. Am J Health Promot 2011;26:101-8.

3. Kaly PW, Heesacker M, Frost HM. Collegiate alcohol use and high-risk sexual behavior: a literature review. J Coll Student Dev. 2002;43:838-50.

4. LaBrie JW, Pedersen ER, Thompson AD, Earleywine M. A brief decisional balance intervention increases motivation and behavior regarding condom use in high-risk heterosexual college men. Arch Sex Behav. 2008;37:330-9.

5. Zhang JH. Survey of drinking status among naval pilots. Aviat Surg. 2000;28: 160-1.

6. Jahnke AS, Haddock CK, Poston WS, Hoffman KM, Hughey J, Lando HA. A qualitative analysis of the tobacco control climate in the U.S. military. Nicotine Tob Res. 2010;12:88-95.

7. Joseph AM, Muggh M, Pearson KC, Lando H. The cigarette manufacturers' efforts to promote tobacco to the U.S. military. Milit Med. 2005;170:874-80.

8. Jiang $\mathrm{YH}, \mathrm{Hu}$ J. An investigation of smoking habits and influencing factors among naval aviators. J Navy Med. 2005;26:47-9.

9. Cowan DN, Bedno SA, Urban N, Yi B, Niebuhr DW. Musculoskeletal injuries among overweight army trainees: incidence and healthcare utilization. Occup Med. 2011;61:247-52.

10. Taanila H, Suni J, Pihlajamaki H, Mattila VM, Ohrankammen O, Vuorinen P, Parkkari J. Aetiology and risk factors of musculoskeletal disorders in physically active conscripts: a follow-up study in the Finnish Defence forces. BMC Musculoskelet Disord. 2010;11:146.

11. Guh DP, Zhang W, Bansback N, Amarsi Z, Birmingham CL, Anis AH. The incidence of co-morbidities related to obesity and overweight: a systematic review and meta-analysis. BMC Public Health. 2009;9:88.

12. Li XL, Liu XN, Zhang DH. BMl-related diseases and index analysis of naval aviators flying different types of aircraft. J Navy Med. 2014;35:339-43.
13. Frayne SM, Parker VA, Christiansen CL, Loveland S, Seaver MR, Kazis LE, Skinner KM. Health status among 28,000 women veterans. J Gen Intern Med. 2006;21:S40-6.

14. Smith TC, Wingard DL, Margaret AK, Donna KS, Slymen DJ, Sallis JF. PTSD prevalence, associated exposures, and functional health outcomes in a large, population-based military cohort. Public Health Rep. 2009;124:90-102.

15. Robyn MH, Larson GE, Kewley SB, Garland CF. Psychiatric diagnoses and punishment for misconduct: the effects of PTSD in combat-deployed marines. BMC Psychiatry. 2010;10:88.

16. Singh JA, Nelson DB, Fink HA, Nichol KL. Health-related quality of life predicts future health care utilization and mortality in veterans with selfreported physician-diagnosed arthritis: the veterans arthritis quality of life study. Semin Arthritis Rheum. 2005:34:755-65.

17. Singh JA, Borowsky SJ, Nugent S, Murdoch M, Zhao Y, Nelson DB, Petzel R, Nichol KL. Health-related quality of life, functional impairment, and healthcare utilization by veterans: Veterans' quality of life study. J Am Geriatr Soc. 2005;53:108-13.

18. Kazis LE, Ren XS, Lee A, Skinner K, Rogers W, Clark J, Miller DR. Health status in VA patients: results from the veterans health study. Am J Med Qual. 1999;14:28-38.

19. Kazis LE, Miller DR, Clark JA, Skinner KM, Lee A, Ren XS, Spiro A, Rogers WH, Ware JE. Improving the response choices on the veterans SF-36 health survey role functioning scales: results from the veterans health study. J Ambul Care Manage. 2004;27:263-80.

20. Kazis LE, Lee A, Spiro A, Rogers W, Ren XS, Miller DR, Selim A, Hamed A, Haffer SC. Measurement comparisons of the medical outcomes study and veterans SF-36 health survey. Health Care Financ Rev. 2004:25:43-58.

21. Jones $D$, Kazis $L$, Lee $A$. Health status assessments using the veterans SF-12 and SF-36: methods for evaluating outcomes in the veterans health administration. J Ambul Care Manage. 2001;24:68-86.

22. Author Coorperative Meta-Analysis Group of Working Group on Obesity in China. The predictive value of BMI and waist circumference on the risk factors in China: study on BMI and waist circumference of the appropriate. Chin J Epidemiol. 2002;23:5-10.

23. Zeng SQ, Lin L. Study on smoking patterns and related factors of residents over 15 years old in Guangdong Province. Chinese J Epidemiol. 2000;21:134-6.

24. Jacobson IG, Ryan MA, Hooper TI, Smith TC, Amoroso PJ, Boyko EJ, Gackstetter GD, Wells TS, Bell NS. Alcohol use and alcohol-related problems before and after military combat deployment. JAMA. 2008;300:663-75.

25. Smith TC, Ryan MA, Smith B, Reed RJ, Riddle JR, Gumbs GR, Gray GC. Complementary and alternative medicine use among US navy and marine corps personnel. BMC Complement Altern Med. 2007;7:16.

26. Jiang MM. Psychometric evaluation, norms, application to chronic conditions of the version 2 of the SF-36 health survey in Chinese population. Zhejiang: Zhejiang University; 2008.

27. Margaret AK, Tyler C, Smith B. Millennium cohort: enrollment begins a 21year contribution to understanding the impact of military service. J Clin Epidemiol. 2007:60:181-91.

28. Wu FZ, Li F, Song YH, Ma J, Mao M, Liu Y, Liu J. The research status of mental health in navy. Prog Mod Biomed. 2014;14:353-5.

29. Liu XR, Chen GL, He X, Gu RP, Liu J, Liu T. Investigation and analysis of mental health status of navy officers and soldiers. People's Army Med Corps 2008;51:338-9.

30. Tian YJ, Miao JY, Liu JC, Wang Q, Wang JB, Ou JJ. Study on the influencing factors of military personnel's quality of life. Hosp Adm in J Chin PLA. 2005; 12:19-21

31. Feng $X G$. An investigation on mental health status and its influencing factors of naval personnel serving at special worksites in south china: The First Military Medical University, Southern Medical University. Guangzhou: 2004

32. Xu T, Li W, Hu B, Chen T, Liu B, Sun Y, Wang Y. Smoking and passive smoking among adults in 11 provinces of China. Chin J Prev Contr Chron Dis. 2010;18:229-30

33. Silva VA, Jayasekera NE, Hanwella R. Smoking among troops deployed in combat areas and its association with combat exposure among navy personnel in Sri Lanka. Subst Abuse Treat Prev Policy. 2012;7:27.

34. Institute of Medicine. Combating tobacco use in military and veteran populations. Washington, DC: National Academic Press; 2009.

35. Ma GS, Zhu DH, Hu XQ, Luan DC, Kong LZ, Yang XG. Status of drinking behavior among Chinese residents. Acta Nutrimenta Sinica. 2005:27:362-5.

36. LeardMann CA, Smith B, Ryan MAK. Do adverse childhood experiences increase the risk of post deployment posttraumatic disorder in US marines? BMC Public Health. 2010;10:437. 
37. Ryan MA, Smith TC, Smith B, Amoroso P, Boyko EJ, Gray GC, Gackstetter GD, Riddle JR, Wells TS, Gumbs G, Corbeil TE, Hooper TI. Millennium cohort: enrollment begins a 21-year contribution to understanding the impact of military service. J Clin Epidemiol. 2007;60:181-91.

38. Wu YF, Ma GS, Hu YH, Li YP, Li X, Cui CH, Chen CM, Kong LZ. Prevalence of overweight and obesity among Chinese residents. Chin J Prev Med. 2005; 139:316-20.

39. Nelson KM. The burden of obesity among a national probability sample of veterans. J Gen Intern Med. 2006;21:915-9.

40. Xie SL, Lin H, Zhang YQ, Shang R, Li ZW, Zhang L. The outpatient disease spectrum and characteristics of navy officers and soldiers during 2009-2011. J Prev Med Chin PLA. 2017;35:12-5.

41. Voelker MD, Saag KG, Schwartz DA, Chrischilles E, Clarke WR, Woolson RF, Doebbeling BN. Health-related quality of life in gulf war era military personnel. Am J Epidemiol. 2002;155:899-907.

42. Darviri C, Fouka G, Gnardellis C, Artemiadis AK, Tigani X, Alexopoulos EC. Determinants of self-rated health in a representative sample of a rural population: a cross-sectional study in Greece. Int J Environ Res Public Health. 2012;9:943-54

Ready to submit your research? Choose BMC and benefit from:

- fast, convenient online submission

- thorough peer review by experienced researchers in your field

- rapid publication on acceptance

- support for research data, including large and complex data types

- gold Open Access which fosters wider collaboration and increased citations

- maximum visibility for your research: over $100 \mathrm{M}$ website views per year

At BMC, research is always in progress.

Learn more biomedcentral.com/submissions 